\title{
Effect of Laser Surface Remelting on the Corrosion Resistance of 316L Orthodontic Brackets
}

\author{
Xiao-Yan ZHANG ${ }^{1}$, Yong ZOU ${ }^{2, *}$, Xiang-Long ZENG ${ }^{3, *}$ \\ ${ }^{1}$ Department of Orthodontics, Beijing Stomatological Hospital, Capital Medical University, Beijing \\ 100006, China \\ ${ }^{2}$ Key Lab of Liquid Structure and Heredity of Materials, Ministry of Education, Shandong University, \\ Jinan 250061, Shandong, China \\ ${ }^{3}$ Department of Orthodontics, School \& Hospital of Stomatology, Peking University, Beijing 100081, \\ China \\ *E-mail: yzou@sdu.edu.cn or zengxl@yeah.net
}

doi: $10.20964 / 110402877$

Received: 12 January 2016 / Accepted: 17 February 2016 / Published: 1 March 2016

To improve its corrosion resistance from artificial saliva, 316L orthodontic brackets were subjected to surface modification by laser remelting. The experimental results showed that the passive films of $316 \mathrm{~L}$ orthodontic bracket in artificial saliva have n-type semiconducting properties. The improvement of $316 \mathrm{~L}$ orthodontic bracket corrosion resistance was found to depend on the laser power. Laser surface remelting decreased the amount of $\delta$ second phase in the $316 \mathrm{~L}$ orthodontic bracket. However, only the appropriate laser power was found to improve its corrosion resistance. Moreover, high laser powers were unable to increase its corrosion resistance. The improved corrosion resistance of $316 \mathrm{~L}$ orthodontic bracket was attributed to the refinement of its grain sizes and homogenization of its surface elements by laser remelting.

Keywords: Laser remelting; Passive film; Corrosion; Bracket

\section{FULL TEXT}

(C) 2016 The Authors. Published by ESG (www.electrochemsci.org). This article is an open access article distributed under the terms and conditions of the Creative Commons Attribution license (http://creativecommons.org/licenses/by/4.0/). 